\title{
DOES HOUSEHOLD FOOD INSECURITY REFLECTS DIET QUALITY OF CHILDREN? A STUDY AMONG THE B40 FAMILIES IN PENDANG, KEDAH
}

\author{
APEERA PRAK CHANG AND ASMA'ALI ${ }^{B^{*}}$. \\ a,b Faculty of Fisheries and Food Science, Universiti Malaysia Terengganu, Kuala Nerus, Terengganu, Malaysia \\ *Corresponding author: asma.ali@umt.edu.my;
}

\begin{abstract}
Food insecurity is interrelated with low food supply consumption which have high disposition to poor diet quality. However, less study has been done in assessing the relationship between food insecurity and diet quality of children in Malaysia. Therefore, this study objectives are to determine food insecurity level and diet quality of children from B40 families in Kedah. This cross-sectional study was carried out among 106 children aged $7-12$ years old from one selected district in Pendang, Kedah. Radimer/Cornell Hunger was used to determine food insecurity level of the children, while diet quality of the children was assessed by applying modified Healthy Eating Index (HEI) 2005. Based on the result, 43.4\% of the household were categorized as food secure while $56.6 \%$ were food insecure. Those food insecure were classified into three levels and the study found that $61.0 \%$ were household food insecure, $28.0 \%$ were individual food insecure and $11.0 \%$ of the household were child hunger. About $28.3 \%$ of them had poor diet quality, $69.8 \%$ of them had diet that needs improvements and only $1.9 \%$ of them had good diet quality. However, there was no significant relationship found between food insecurity and diet quality of these children $(p=0.436)$. This is somehow indicated that food insecurity does not reflect the diet quality of children from the B40 families in this study.
\end{abstract}

Keywords: Food insecurity, diet quality, healthy eating index, Malaysia

\section{Introduction}

Food insecurity transpires when not all people always have ability to access sufficient or enough foods for an active and healthy lifestyle (Food and Agriculture Organization [FAO], 2009). Households with food insecurity are associated with larger family size, more school-age children and mother as a housewife (Alam et al, 2016). Upsurge of food insecurity households may be caused by high domestic food prices, low incomes and increment of unemployment (FAO, 2009). Food insecurity of households has always been related to low socio-economic status, inadequate dietary intakes, poor nutritional status, poor diet quality and uncertainty of food supply (Naser et al., 2014). Low socio-economic status commonly reflected in household that have small monthly income, little income per capita, low educational level, unemployment among adult household members and single female-headed households (Shariff \& Ang, 2001).

Kedah recorded a somewhat high overall poverty level of $7 \%$ in 2004 compared to the overall poverty rate of $5.7 \%$ (Che Mat et al., 2011 and UNDP, 2004). These indicators can be echoed by a study conducted in Pendang, Kedah which reported that about $23 \%$ of households were food insecure while almost $77 \%$ faced some food insecurities (Masron et al., 2014). A study in Bachok, Kelantan also reported that approximately $30 \%$ of the households were food insecure (Naser et al., 2014). Meanwhile, more than $50 \%$ of the households in Sabak Bernam, Selangor experienced some degree of food insecurity and $34.5 \%$ reporting child hunger (Shariff \& Khor, 2008).

Diet quality measures the variety and nutrient adequacy of one's diets (Sealey-Potts \& Potts, 2014). Most of the children from a food 
insecure household are experiencing inadequate intake of food and some suffer from hunger. It may become a barrier for children from food insecure household to receive nutritious diets when food budgets are stretched (Food Insecurity, 2016). However, less study has been done in assessing the relationship between food insecurity and diet quality in Malaysia. Therefore, the objectives of this study are to assess food insecurity level and diet quality as well as to determine the relationship between food insecurity and diet quality of children from B40 families in Pendang, Kedah. This study aligns with the nutrition research gaps highlighted in the Nutrition Research Priorities in Malaysia for the 11th Malaysia Plan (20162020) which warrant a further study on diet adequacy of low-income children in Malaysia.

\section{Materials and Methods}

This cross-sectional study was conducted in Pendang, Kedah. Six villages selected through multistage simple random sampling were involved in this study; Kampung Alor Besar, Kampung Padang Peninjau, Kampung Bukit Kobah, Kampung Bukit Choras, Kampung Lang Merah and Kampung Bukit Raya Dalam. The sample size required was calculated by using Cochran's formula at $95 \%$ of confidence level, 0.08 of absolute error or precision, and proportion of $23 \%$ based on food insecurity prevalence in Kedah (Masron, 2014). Thus, the minimum calculated sample size was 106 respondents. The eligible criteria of the respondents were either male or female children of low-income family aged between 7 to 12 years old. Besides, monthly household income of their family must be below than RM 2537 to meet the B40 criteria (Eleventh Malaysia Plan, 2016). Ethical approval was obtained from the Human Research Ethics Committee of UMT with the reference number of UMT/JKEPM/2018/29.

In this study, a questionnaire consisting of three parts were disseminated via home to home visit. Both researcher-administered and selfadministered approaches were used to obtain part $\mathrm{A}$ and $\mathrm{B}$, and part $\mathrm{C}$, respectively. Part A consist of 12 questions regarding to socio-demographic information of the respondents. This included gender, age, races, religion, education level and occupational status of mother and father, household size, food assistance provision, financial assistance support and monthly household income. Part B of the questionnaire was the assessment of household food insecurity level by using Radimer / Cornell Hunger and Food Insecurity Instrument. Radimer / Cornell Hunger and Food Insecurity was used to determine the severity level of food insecurity regarding a certain household (Mohamadpour et al., 2012). This instrument comprises of 10 items which depict quantity of food, quality of food, food acceptability and certainty of getting food. Each household food insecurity assessment was classified into 4 categories; food secure, household food insecure, individual food insecure or child hunger based on the responses of the respondents. Three answer were provided for each item which were "not true", "sometime true" and "often true". "Not true" was considered as a negative answer while "sometime true" and "often true" were considered as a positive answer. Positive and negative answers given by the respondents determined their household categories as shown in Table 1 below. When negative answers were obtained in all hunger and food insecurity items, the household was considered as food secure. Next, if there are positive answers in item 1 to 4 , this reflect household food insecure. Individual food insecurity exists when positive answers appear in item 5 to 8 but not in item 9 to 10 . The household is considered as child hunger if positive answers appeared in item 9 to 10 .

Table 1: Classification of severity of food insecurity

\begin{tabular}{ll}
\hline $\begin{array}{l}\text { Level of food } \\
\text { insecurity }\end{array}$ & \multicolumn{1}{c}{ Answer } \\
\hline Food Secure & $\begin{array}{l}\text { Negative answers for all hunger } \\
\text { and food insecurity items }\end{array}$ \\
$\begin{array}{l}\text { Household } \\
\text { Insecure }\end{array}$ & $\begin{array}{l}\text { Positive answers between items } 1 \\
\text { to } 4 \text { but not to individual or child } \\
\text { level items }\end{array}$ \\
$\begin{array}{l}\text { Individual } \\
\text { Insecure }\end{array}$ & $\begin{array}{l}\text { Positive answer between item } 5 \text { to } \\
\text { Child Hunger not to item } 9 \text { to } 10\end{array}$ \\
\hline
\end{tabular}


Negative answers: "Not true"

Positive answers: "Sometimes true" or "often true"

For part C, it encompasses two days (one weekday and one weekend) of dietary record for children's diet quality assessment. The children assisted by their parents were required to record their foods and beverages consumption and describe it as precisely as possible including specific types of food and serving size. A Malaysian food album with many local food photos was given to the respondents in order to help them recognized the household measurement and serving size of the food. The dietary record was analyzed using Nutrition Pro Diet Analysis software. The data was then used to determine the diet quality of children through a modified Healthy Eating Index (HEI) 2005. This modified Healthy Eating Index (HEI) 2005 was based on a study by Rezali et al., (2015) as they described it as the Healthy Eating Index for Malaysian. Modified Healthy Eating Index (HEI) 2005 consist of nine components which are grains, vegetables, fruits, milk and milk product, poultry, meat and egg, fish, legumes, energy percentage from total fat and sodium. Each component in HEI had a range score from 0 to 10 . For component one to seven, a maximum score of 10 was given if the recommendation serving size of a component was achieved whereas minimum score of zero was given when there was no consumption at all. Intermediate score was calculated proportionately when they consume in between the recommended serving size. For component eight and nine, maximum score of 10 was given when the respondents manage to not go beyond the recommended serving size and vice versa. The composite score of HEI ranged from zero to 100. A total score of above 80 is classified as good, scores between 51 and 80 indicated the needs of improvement, and scores of less than 51 is considered poor. Thus, higher score of HEI indicates better diet quality. All data were analyzed using SPSS version 20.0. Kolmogorov-Smirnov test was used to test the normality due to the sample size more than 50. Normally distributed data was presented using mean and standard deviation whereas non-normally distributed data was presented in median and inter quartile range. Spearman correlations coefficient was performed in assessing relationship between food insecurity and diet quality of children from low-income at significant level of $\mathrm{p}<0.05$.

\section{Results and Discussion}

\section{Socio-demographic information}

Among 106 children from this B40 families, $53.8 \%$ of them were male whereas $46.2 \%$ of the respondents were female as shown in Table 2. Most of the respondents were Malay, aged 10 years old and their parents' highest level of education were until secondary school only. Majority of the father's children were selfemployed because most of them were paddy farmers whereas the greater part of the mother's children were mainly housewives. About $54.7 \%$ and $58.5 \%$ of respondents received food assistance of food assistance program (RMTRancangan Makanan Tambahan) and financial assistance from Malaysia Ministry of Education (KWAMP- Kumpulan Wang Amanah Pelajar Miskin). As for household monthly income, approximately $34.9 \%$ of the households had less than RM1000, while $29.2 \%$ and $22.6 \%$ of the household had income between RM1000 to RM1499 and RM1500 to RM1999, respectively.

Table 2: Socio-demographic information of respondents $(\mathrm{n}=106)$

\begin{tabular}{ccc}
\hline Variable & $\mathrm{n}(\%)$ & $\begin{array}{c}\text { Median } \\
(\mathrm{IQR})\end{array}$ \\
\hline Gender of children & & \\
Male & $57(53.8)$ & \\
Female & $49(46.2)$ & \\
\hline Age of children (years) & & $10.0(3.0)$ \\
7 & $17(16.0)$ & \\
8 & $16(15.1)$ & \\
9 & $16(15.1)$ & \\
10 & $22(20.8)$ & \\
11 & $12(11.3)$ & \\
12 & $23(21.7)$ & \\
\hline
\end{tabular}




\begin{tabular}{cc}
\hline Ethnicity of children & \\
Malay & $76(71.7)$ \\
Chinese & $4(3.8)$ \\
Siamese & $26(24.5)$ \\
\hline Religion of children & \\
Islam & $76(71.7)$ \\
Buddhism & $30(28.3)$ \\
\hline Education of father & \\
Primary school & $7(6.6)$ \\
Secondary school & $82(77.4)$ \\
Certificate/ Diploma & $15(14.2)$ \\
Degree & $2(1.9)$ \\
\hline Education of mother & \\
Primary school & $6(5.7)$ \\
Secondary school & $91(85.8)$ \\
Certificate/ Diploma & $8(7.5)$ \\
Others & $1(0.9)$ \\
\hline
\end{tabular}

\begin{tabular}{cc}
\hline Occupation of father & \\
Self employed & $67(63.2)$ \\
Government sector & $8(7.5)$ \\
Private sector & $31(29.2)$ \\
\hline Occupation of mother & \\
Housewife & $77(72.6)$ \\
Self employed & $12(11.3)$ \\
Government sector & $1(0.9)$ \\
Private sector & $16(15.1)$ \\
\hline Household size & \\
3 & $4(3.8)$ \\
4 & $16(15.1)$ \\
5 & $43(40.6)$ \\
6 & $21(19.8)$ \\
7 & $11(10.4)$ \\
8 & $6(5.7)$ \\
9 & $5(4.7)$ \\
\hline Yes & $58(54.7)$ \\
No & $48(45.3)$ \\
\hline Food assistance (RMT) & \\
\hline
\end{tabular}

\begin{tabular}{cc}
\hline $\begin{array}{c}\text { Financial assistance } \\
\text { (KWAPM) } \\
\text { Yes }\end{array}$ & $62(58.5)$ \\
No & $44(41.5)$ \\
\hline $\begin{array}{c}\text { Household monthly } \\
\text { income(RM) } \\
<1000\end{array}$ \\
$1000-1499$ & $37(34.9)$ \\
$1500-1999$ & $24(22.6)$ \\
$2000-2499$ & $14(13.2)$ \\
\hline
\end{tabular}

*Notes:

RMT - Rancangan Makanan Tambahan

KWAPM- Kumpulan Wang Amanah Pelajar Miskin

\section{Food Insecurity Status}

Almost $43.4 \%$ of the households were classified as food secure while the remaining 56.6\% were food insecure. According to Farhadian et al., (2015), 35.3\% of the household in Sabah were categorized as food secure. Meanwhile, a study in Bachok, Kelantan stated that $16.1 \%$ of the households were food secure (Naser et al., 2014). As can be seen from the comparison, the proportion of food secure households was higher than those two previous studies in Sabah and Kelantan. This result may be explained by the fact that most of the households in this study had an average of monthly household income more than RM 1000 which perhaps can maintain their household food supply. Currently, $42.0 \%$ of the households in Sabak Bernam, Selangor was categorized as food secure among the overall households (Shariff \& Khor, 2008). The proportion of food secure households in this study was almost the same as the study in Sabak Bernam mainly due to households in both studies plan their expenditure properly to ensure that money for food can be stand until end of the month (Norhasmah et al., 2010).

Table 3: Food insecurity status of household $(\mathrm{n}=106)$

\begin{tabular}{lc}
\hline Variable & $\mathrm{n}(\%)$ \\
\hline Food insecurity & \\
Food Secure & $46(43.4)$ \\
Food insecure & $60(56.6)$ \\
\hline
\end{tabular}




\section{Level of Food Insecurity}

All the food insecure respondents $(n=60)$ were classified based on the level of food insecurity either household insecure, individual insecure or child hunger as shown in Table 4 . About $61 \%$ of them reported to experience household insecure. Previous studies done in Pengkalan Kubor, Kelantan (Nasihah et al., 2017) and Kuala Lumpur(Sharif\&Ang, 2001) reported that $38.7 \%$ and $27.7 \%$ of the respondents were household insecure, respectively. Thus, the findings in this study were higher compared to those of other studies. This result may be explained by the fact that the fathers' respondents were mainly paddy farmer in which the monthly household income are highly reliant on the paddy production. At times, the household expenditure may surpass their household income for several months. Therefore, it could be one of the factors that cause high household food insecurity among the B40 families in this study. Apart from that, 28\% of the household were categorized as individual food insecure. This percentage is somehow higher than a study in Negeri Sembilan which only $19.5 \%$ of respondents were individual food insecure (Mohamadpour et al., 2012) but similar to a study done in Kelantan with $29.6 \%$ from the overall households were individual food insecure (Naser, 2014). Moreover, 11\% of the households were classified as child hunger. However, proportion of child hunger in previous studies were higher compared to this study where Kelantan (Nasihah et al.,2017), Kuala Lumpur (Sharif \& Ang, 2001) and Sabak Bernam, Selangor (Shariff \& Khor., 2008) reported $22.5 \%, 27 \%$ and $34.5 \%$ of the household suffer from child hunger, respectively. This rather unforeseen finding could be due to the mothers that might be under-reporting or hiding the truth about dietary adequacy of food in the households due to embarrassment for not being able to provide sufficient needs for their children (Mohamadpour et al., 2012). However, it could be possible that the food assistance (RMT) and financial assistant (KWAPM) received by the children in this study would likely to lower the percentage of child hunger in a household.
Table 4: Level of food insecurity of household

$$
(n=60)
$$

\begin{tabular}{lc}
\hline Variable & $\mathrm{n}(\%)$ \\
\hline Household Insecure & $50(61.0)$ \\
Individual Insecure & $23(28.0)$ \\
Child Hunger & $9(11.0)$ \\
\hline
\end{tabular}

*One individual can experience more than one level of food insecure at a time.

\section{Diet Quality of Children from B40 Family}

As can be seen from the Table 5, both male and female had high median score for grain. This is because they consume high intake of rice, bread and noodle in their daily routine. The median/ mean score of fruit and vegetables was higher for female than male. This showed that female consume more fruits and vegetables than male. This is supported by Rasmussen et al., (2006) where male had lower intake of fruits and vegetables than female due to preference, taste, texture and appearance. The median score for milk and legume components for both male and female were low. This study produced results which corroborate the findings that majority of children in Malaysia consume a smaller amount of legume and milk and milk products than recommended (Koo et al., 2016).

The median score of poultry, meat and egg for both male and female had met the recommended intake. This finding is consistent with that of Koo et al., (2016) who stated that majority of the children in Malaysia met the recommendation for meat and poultry. It can be understood that the children consume high intake of either chicken, beef or egg in daily life. It is intriguing to find out that the mean score of fish consumption for both male and female were also high. This might be due to the affordable price of fish for routine consumption. Lastly, the mean score for energy percentage from total fat and sodium for female was higher than male. This indicate that female children tend to consume more high fat and sodium food than male. The mean of total healthy eating index (HEI) score was $57.1 \pm 11.0$. It indicate that most of the 
respondents were categorized as having diet that needs improvement. This may be in line for the low consumption of milk and legume but high consumption of fat and sodium.

Table 5: Median or mean score of HEI components

\begin{tabular}{|c|c|c|c|}
\hline \multirow{2}{*}{$\begin{array}{c}\text { HEI } \\
\text { Components }\end{array}$} & \multirow{2}{*}{$\begin{array}{c}\text { Possible } \\
\text { Range of } \\
\text { Score }^{\mathrm{a}}\end{array}$} & Male & Female \\
\hline & & $\begin{array}{c}\text { Mean } \\
\pm \text { SD / } \\
\text { Median } \\
\text { (IQR) }\end{array}$ & $\begin{array}{l}\text { Mean } \\
\pm \text { SD / } \\
\text { Median } \\
\text { (IQR) }\end{array}$ \\
\hline Grains & 0 to 10 & $10.0(2.4)$ & $\begin{array}{l}10.0 \\
(1.6)\end{array}$ \\
\hline Vegetables & 0 to 10 & $3.3(3.2)$ & $4.2 \pm 2.1$ \\
\hline Fruit & 0 to 10 & $3.8(10.0)$ & $6.1(8.1)$ \\
\hline $\begin{array}{l}\text { Milk and } \\
\text { Milk } \\
\text { Product }\end{array}$ & 0 to 10 & $0.8(1.3)$ & $0.0(1.3)$ \\
\hline $\begin{array}{l}\text { Poultry, } \\
\text { Meat and } \\
\text { Egg }\end{array}$ & 0 to 10 & $10.0(0.0)$ & $\begin{array}{l}10.0 \\
(0.0)\end{array}$ \\
\hline Fish & 0 to 10 & $10.0(0.6)$ & $\begin{array}{l}10.0 \\
(0.6)\end{array}$ \\
\hline Legumes & 0 to 10 & $0.0(0.0)$ & $0.0(0.7)$ \\
\hline $\begin{array}{c}\% \text { of energy } \\
\text { from total } \\
\text { fat }\end{array}$ & 0 to 10 & $0.0(10.0)$ & $\begin{array}{c}10.0 \\
(10.0)\end{array}$ \\
\hline Sodium & 0 to 10 & $10.0(10.0)$ & $\begin{array}{c}10.0 \\
(10.0)\end{array}$ \\
\hline $\begin{array}{l}\text { Total HEI } \\
\text { score }\end{array}$ & $\begin{array}{c}57.1 \pm \\
11.0\end{array}$ & & \\
\hline
\end{tabular}

${ }^{a}$ Higher score indicate better diet quality

As can be seen from the Table 6, only around $2 \%$ of the respondents were categorized as having good diet quality while the remaining either need improvement or having poor diet quality. According to Tek et al., (2011), generally children had poor diet quality for the reason of low consumption of dairy product, vegetables and fruit. The respondents mainly had HEI score between the ranges of 51 to 80 indicate that their diet need improvement. These results reflect those of Rauber et al., (2014) who also found that most of 7 to 8 years old respondents in Brazil also had diet quality score between the ranges of 51 to 80 . This result may be explained by the fact that children tend to consume higher energy dense food, fat, sugar and sodium (Rauber et al., 2014).

Table 6: Healthy Eating Index (HEI) Score

\begin{tabular}{lcc}
\hline $\begin{array}{c}\text { Healthy Eating } \\
\text { Index (HEI) } \\
\text { Score }\end{array}$ & Rating & $\mathrm{n}(\%)$ \\
\hline Less than 51 & Poor & $30(28.3)$ \\
$51-80$ & $\begin{array}{l}\text { Needs } \\
\text { Improvement }\end{array}$ & $74(69.8)$ \\
More than 80 & Good & $2(1.9)$ \\
\hline
\end{tabular}

\section{Relationship between total Food Insecurity and Diet Quality of Children from B40 Family}

Spearman correlation coefficient was used to determine the relationship between food insecurity and diet quality of children in this study. Contrary to expectations, this study did not find a significant relationship between food insecurity and diet quality, $\mathrm{p}=0.436$ as shown in Table 7. Although, these results differ from some published studies (Davidson, 2017; Hanson \& Connor, 2014), they are consistent with those of Marshall (2010). This finding broadly supports the work of other few studies that shows food insecurity was less associated with dietary quality in children (Marshall, 2010). A possible explanation for these results may be due to dietary intake of children was reported by parents in which they may tend to under- or over-reporting their children dietary intake (Hanson \& Connor, 2014).

Table 7: Relationship between Food Insecurity and Diet Quality

\begin{tabular}{|c|c|c|}
\hline & \multicolumn{2}{|r|}{ Food insecurity } \\
\hline & p-value & Correlation Coefficient (r) \\
\hline HEI Score & 0.436 & -0.077 \\
\hline
\end{tabular}

* Correlation is significant at $\mathrm{p}<0.05$ (2 tailed $)$

\section{Conclusion}

This study set out to explore the influence household food insecurity towards diet quality of children from the B40 families in Pendang, 
Kedah. This study has identified that more than half of the houshehold were categorized as household food insecure with a need for improvement in terms of their children diet quality. The most obvious finding to emerge from this study is that there was no significant relationship between food insecurity and diet quality among the children in this study. This indicate that food insecurity does not have a sturdy influence towards the diet quality of children from low-income family in this study.

\section{Acknowledgements}

The authors would like to express their thanks to all the respondents and their families in Pendang, Kedah for their greatest cooperation in completing the questionnaire and willingness to keenly convoluted in this research.

\section{References}

Alam, M.M., Siwar, C., Wahid, A.N.M. \& Talib, B. (2016). Food Insecurity and Low-income Households in the Malaysian East Coast Economic Region: An Empirical Analysis. 28(1), 2- 15.

Che Mat, S.T., Abu Bakar, N.A. \& Abdul Jalil, A.Z. (2011). The Impact of Non-Farm Income on the Incidence of Poverty among Farmers in Kedah, Malaysia. International Journal of Trade, Economics and Finance, 2(4), $326-330$.

Davison, K.M., Gondara, L. and Kaplan, B.J. 2017. Food Insecurity, Poor Diet Quality, and Suboptimal Intakes of Folate and Iron Are Independently Associated with Perceived Mental Health in Canadian Adults. Nutrients, 9(3), 274.

Eleventh Malaysia Plan. 2016 - (2020) [online]. Available from: https:// www.talentcorp.com.my/clients/ TalentCorp_2016_7A6571AE-D9D04175-B35D-99EC514F2D24/contentms/ img/publication/RMKe-11\%20Book.pdf [Accessed on 16 May 2018].
Farhadian, A., Chan, V.S.H. \& Farhadian, H. (2015). Addressing Household Food Insecurity using the Household Food Insecurity Access Scale (HFIAS) in a Poor Rural Community in Sabah, Malaysia. International Journal of Humanities and Social Science Invention, 4(8), 89 - 100.

Food and Agriculture Organization. (2009). The State of Food Insecurity in the World [online]. Available from http://www.fao. org/3/a-i0680e.pdf [Accessed on 12 April 2018].

Food Insecurity: A Public Health Issue. 2016. Public Health Reports, 131(5), 655657.

Hanson, K.L. \& Connor, L.M. (2014). Food Insecurity and Dietary Quality in US Adults and Children: A Systematic Review. The American Journal of Clinical Nutrition, 100(2), $648-692$.

Koo, H.C., Lee, S.T., Poh, B.K. \& Bragt, M.C.E. (2016). Are Malaysian Children Achieving Dietary Guideline Recommendations? Asia- Pacific Journal of Public Health, 28(5), 1- 13.

Marshall, E. L. (2010). Examining the Relationship between Weight, Food Insecurity, Food Stamps, and Perceived Diet Quality in School-aged Children. University of Kentucky Master's Theses, $1-61$.

Masron, T., Abdul Gapor, S. \& Ismail, N. (2014). Spatial Mapping of Food Security in Mukim Pendang, Kedah. Academic Journal of Interdisciplinary Studies, 3(4), $349-360$.

Mohamadpour, M., Sharif, Z.M. and Keysami, M.A. (2012). Food Insecurity, Health and Nutritional Status among Sample of Palmplantation Households in Malaysia. Journal of Health Population and Nutrition, 30(30), $291-302$. 
Naser, I.A., Jalil,R., Wan Muda, W.M., Wan Nik, W.S., Shariff, Z.M. \& Abdullah, M.R. (2014). Association between Household Food Insecurity and Nutritional Outcomes among Children in Northeastern of Peninsular Malaysia. Nutrition Research and Practice, 8(3), 1-8.

Nasihah, A.N., Asma, A. \& Salihah, N. (2017). Assessing Food Insecurity and Its Association with Nutritional Status of Children in Pengkalan Kubor, Kelantan. International Conference on Food Science and Nutrition, 10- 15.

Norhasmah, S., Zalilah, M.S., Mohd Nasir, M.T., Kandiah, M. \& Asnarulkhadi, A.S. (2010). A Qualitative Study of Coping Strategies among Women from Food Insecurity Households in Selangor and Negeri Sembilan. Malaysia Journal of Nutrition, 16(1), 39 - 54. 1.

Nutrition Research Priorities in Malaysia. For 11th Malaysia Plan (2016-2020). Ministry of Health Malaysia. 2016.

Rasmussen, M., Krolner, K., Kleppp, K.I., Lytle, L., Brug, J., Bere, E. \& Due, P. (2006). Determinants of Fruit and Vegetable Consumption among Children and Adolescents: A review of the Literature. International Journal of Behavioral Nutrition and Physical Activity, 3(2), 1-19.

Rauber, F., Louzada, M.L.C. \& Vitolo, M.R. (2014). Healthy Eating Index Measures Diet Quality of Brazilian Children of Low Socioeconomic Status. Journal of the American College of Nutrition, 33(1), 26 31.
Rezali, F.W., Chin, Y.S., Shariff, Z.M., Mohd Yusof, B.N., Sanker, K. \& Woon, F.C. (2015). Evaluation of Diet Quality and Its Associated Factors among Adolescents in Kuala Lumpur, Malaysia. Nutrition Research and Practice, 9(5), 511-516.

Sealey-Potts, C. \& Potts, A.C. (2014). An Assessment of Dietary Diversity and Nutritional Status of Preschool Children. Journal of Nutrition and Food Science, 2(7), $1-5$.

Shariff, Z.M. \& Ang, M. (2001). Assessing of Food Insecurity among Low Income Households in Kuala Lumpur Using the Radimer/ Cornell Food Insecurity Instrument - A Validation Study. Malay Journal Nutrition, 7(1), 15-32.

Shariff, Z.M. \& Khor, G.L. (2008). Household Food Insecurity and Coping Strategies in a Poor Rural Community in Malaysia. Nutrition Research and Practice, 2(1), 26 -34 .

Tek, N.A., Yildiran, H., Akbulut, G., Bilici, S., \& Koksal, E. (2011). Evaluation of Dietary Quality of Adolescents Using Healthy Eating Index. Nutrition Research and Practice, 5(4), 322- 328.

UNDP, 2004. "Malaysia measuring and monitoring poverty and inequality". Economic Planning Unit, Jabatan Perdana Menteri, 2007. 